\title{
Approach to concurrent coronary and carotid artery disease: Epidemiology, screening and treatment
}

\author{
Patrícia Feitosa Frota dos Reis ${ }^{1}$, Pedro Vieira Linhares ${ }^{1}$, Fábio Grunspun Pitta ${ }^{1}$, Eduardo Gomes Lima ${ }^{1 *}$ \\ ${ }^{1}$ Department of Atherosclerosis, Instituto do Coração do Hospital das Clínicas da Faculdade de Medicina da USP (InCor-HCFMUSP), São Paulo, SP, Brazil
}

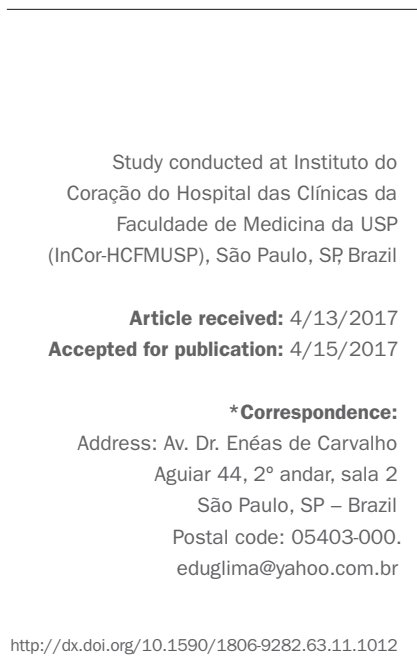

\section{SUMMARY}

The concomitance between coronary artery disease and carotid artery disease is known and well documented. However, it is a fact that, despite the screening methods for these conditions and the advances in surgical treatment, little has been achieved in terms of reducing the risk of complications in the perioperative period. Publications are scarce, being mostly composed of reports or case series. There is little agreement on the best initial therapeutic approach (myocardial versus carotid revascularization) or the best technique to be used (surgery with or without extracorporeal circulation, hybrid treatments, etc.). The authors performed a review of the evidence in this clinical scenario, raising pragmatic questions that help in the therapeutic decision.

Keywords: coronary disease, carotid artery diseases, myocardial revascularization.

\section{INTRODUCTION}

Cerebrovascular accident (CVA), or stroke, is a perioperative complication that occurs in about $2 \%$ of myocardial revascularization $(\mathrm{CABG})$ surgeries. ${ }^{1}$ Evidence suggests that the main etiology is the macroembolization of atherothrombotic debris derived from the aortic arch. ${ }^{2}$

An important subgroup of risk for such complication is that of patients with significant carotid stenosis (> 70\%). However, it has been demonstrated in some studies that this is also a predictor of severe atherosclerotic disease in the aortic arch. ${ }^{3}$ Therefore, the presence of significant carotid stenosis seems to serve more as a marker of risk for aortic arterial disease than as a causal relationship for CVA in the perioperative period of CABG. ${ }^{4}$

Although carotid Doppler ultrasound (USG) screening is routinely performed for preoperative CABG assessment in many institutions, the benefit of carotid revascularization surgery (CAR) in asymptomatic patients is questioned. ${ }^{5}$

Therapeutic choice in patients with coronary artery disease (CAD) and concomitant carotid disease is also controversial, based on few studies and the experience of institutions. Therapeutic strategies include: 1 . combined surgery (CABG and CAR in the same procedure); 2. staged surgeries (CABG with subsequent CAR $x$ CAR with subsequent $\mathrm{CABG}$ ); 3 . hybrid procedure (CABG with percutaneous carotid intervention - PCI). The strategies can be simultaneous or staged, being performed in one or two surgical times, respectively. ${ }^{6,7}$

\section{Carotid artery disease screening IN THE PREOPERATIVE PERIOD OF MYOCARDIAL REVASCULARIZATION}

Currently, there is a strong tendency to request USG carotid Doppler as part of preoperative assessment of CABG. In patients undergoing $C A B G$, the prevalence of major carotid disease is known to range from 2.8 to $22 \%$. On the other hand, among patients undergoing endarterectomy, the prevalence of coronary artery disease is between 28 and $40 \%{ }^{8}$ Despite the strong association between diseases, the incidence of CVA in patients submitted to CABG is low, varying from 1.3 to $2.0 \%{ }^{5}$

The etiology of perioperative CVA is multifactorial, the most common being embolism calcified plaques. According to a meta-analysis by Naylor and Bown, ${ }^{9}$ the incidence of ipsilateral CVA combined with important asymptomatic ipsilateral carotid stenosis is low, only $2 \%$. Note that the main etiologies are related to the procedure per se, such as pressure control, diastolic pulmonary hypertension, atherothrombotic macroembolization during aortic clamping and cannulation, and microembolization of platelet aggregates caused by a swirling flow in cardiopulmonary bypass. ${ }^{10}$

Risk factors for perioperative CVA are: previous CVA or transient ischemic attacks (TIA), peripheral arterial 
disease, systemic arterial hypertension, advanced age $(>65$ years), left ventricular dysfunction, obstructive carotid disease and atrial fibrillation. ${ }^{5}$ Although risk factors help in the stratification of patients undergoing surgery, Durand et al. ${ }^{11}$ created an algorithm based on the characteristics of the patients in an attempt to predict the occurrence of carotid disease, finding a high false-positive rate and low specificity.

Doppler USG has proved to be a very accurate test in the quantification and definition of carotid disease, and it is useful to define patients with a high risk of atherothrombotic events ranging from $3 \%$, in the case of asymptomatic patients with unilateral stenosis from 70 to $99 \%$, to $7-11 \%$ in carotid occlusion. Although this is a cost-effective screening test, there is no study to justify its routine large-scale use in an attempt to reduce morbidity and mortality, so it should be used in selected patients as directed by the Society of Thoracic Surgeons and the American College of Cardiology. ${ }^{12}$ According to the 2014 European directive on myocardial revascularization, Doppler USG is indicated in the preoperative context for patients with a history of CVA or TIA, in addition to carotid bruit. Its utility should also be considered in patients with peripheral obstructive arterial disease, elderly individuals (> 70 years), and in multi-vessel coronary disease. ${ }^{13}$

\section{SCREENING OF CORONARY ARTERY DISEASE IN THE PREOPERATIVE WORKUP OF CAROTID ARTERY REVASCULARIZATION}

While prevalence of significant carotid disease among CABG candidates is low, this seems to be different in a reverse context. The association between carotid and coronary atherosclerosis is very prevalent, consisting of 46 to $71 \%$ in patients undergoing elective vascular surgery. ${ }^{14,15}$ Despite the high prevalence, there is little consensus among cardiologists regarding the stratification of coronary disease in patients with no evidence of angina or anginal equivalent. Illuminati et al. ${ }^{14}$ randomized two groups of patients, asymptomatic from a cardiovascular standpoint, either with indication of endarterectomy for coronary angiography (CINE) or not, with further treatment using percutaneous angioplasty or surgical revascularization. All patients were maintained with dual-antiplatelet therapy (ASA $100 \mathrm{mg}$ + clopidogrel $75 \mathrm{mg}$ ) and high-potency statin. In the comparison of the group of patients undergoing CINE with those that did not receive this treatment, a substantial difference was found in the prevalence of acute myocardial infarction (AMI), respectively 1.4 and $15.7 \%$. Despite the optimistic data, the severity of the patients in this study was low, being mostly uniarterial or biarterial, asymptomatic and without ventricular dysfunction, with only two indications of surgical revascularization. It is also important to note the excess of interventions in patients with chronic coronary artery disease, who would probably have a good long-term prognosis in optimized clinical treatment.

According to the II Guideline for Perioperative Evaluation of the Brazilian Society of Cardiology ${ }^{16}$ patients with intermediate risk for CAD according to the Lee criteria, with an indication for vascular surgery, should undergo noninvasive tests for diagnosis of CAD: stress myocardial perfusion imaging (scintigraphy), exercise stress test or pharmacologic stress echocardiography. The indication of CINE should be reserved for patients with non-invasive tests suggestive of high risk or patients with acute coronary syndrome. ${ }^{16}$

\section{Management of dual-antiplatelet therapy}

According to the current literature, there is no consensus on the management of antiplatelets in this setting. ASA dosage is $100-325 \mathrm{mg} /$ day and clopidogrel dosage is $75 \mathrm{mg} /$ day, ${ }^{9}$ with some reports of clopidogrel loading dose of $600 \mathrm{mg}$ approximately 4 hours before endarterectomy or carotid angioplasty. When choosing between staged procedures, if patient is using DAPT there is a tendency to maintain ASA and to suspend clopidogrel at least 5 days prior to CABG, but it is important to assure the mandatory period of 3-4 weeks of DAPT after carotid stenting, which can delay CABG ${ }^{17}$ In some patients with limiting CCSIII-IV angina, Lopes et al. ${ }^{18}$ chose to maintain double antiaggregation and perform CABG soon after clinical stabilization after carotid angioplasty.

According to the protocol for update and focus on arterial vascular surgery of the II Guideline for Perioperative Evaluation of the Brazilian Society of Cardiology, ${ }^{16}$ ASA should be maintained at a dosage of 75 to $100 \mathrm{mg} /$ day. Regarding the use of clopidogrel, the risk of bleeding inherent to the procedure should be considered. When the risk is moderate or high, clopidogrel should be discontinued five days prior (recommendation grade I, level of evidence $\mathrm{C}$ ), and when the risk of bleeding is low, the antiaggregant should be maintained in the perioperative period.

\section{Combined coronary and Carotid SURGICAL REVASCULARIZATION VERSUS STAGED SURGICAL REVASCULARIZATION}

There is great divergence of opinion as to the best way to approach simultaneous carotid and coronary disease. According to a meta-analysis by Fareed et al., ${ }^{10}$ the safest and lowest mortality rates for CVA and AMI would be to 
perform endarterectomy synchronously to CABG without extracorporeal circulation (ECC).

On the other hand, when evaluating data by Naylor and Bown ${ }^{9}$ regarding studies from 1972 to 2002, results opposite those of Fareed et al. are observed..$^{10}$ The worst outcomes, including overall mortality, composite endpoint of death + CVA and death + CVA + AMI were higher in patients submitted to synchronized surgery, respectively 4.6, 7.4, 8.7 and $11.5 \%$ compared with staged procedures. However, the incidence of CVA alone, both ipsilateral in major carotid disease and CVA in any territory, was higher in CABG prior to CAR; and the rate of AMI alone was higher in patients submitted to CAR preceding CABG. It is important to mention that the majority of patients were asymptomatic from a neurological point of view, and there was no standardized way to diagnose perioperative AMI, which was therefore underdiagnosed.

Despite the divergence among studies, much can be asked about the actual prevalence of CVA combined with carotid disease. The fact is that most CVAs were diagnosed after 24 hours of surgery, regardless of the territory of carotid disease, and many of the patients did not have significant carotid atherosclerosis.

According to recommendations by Masabni et al., when choosing a carotid approach prior to $\mathrm{CABG}$, both procedures should be avoided at the same anesthetic time due to the risk associated with hyperperfusion syndrome after carotid revascularization, making it imperative to observe level of consciousness and neurological parameters shortly after the procedure. Another logical approach is that performed by the team of Seyed Ebrahim, ${ }^{19}$ at the Tehran Heart Center, which advocates prioritizing the treatment of the most severe entity: in patients with symptoms of unstable angina or asymptomatic carotid disease, only CABG is performed; while in patients with stable coronary disease and symptomatic carotid stenosis, the approach advocated is that of carotid artery simultaneously with CABG. The common sense is that the CAR option is based on patient comorbidities, CABG urgency, supra-aortic vessel anatomy and medical center experience. ${ }^{13}$

Such heterogeneity in the results of studies comparing surgical techniques to approach these two entities reflects the limited evidence in this scenario: the studies are mostly single-center studies composed of series of cases with selection bias, so that the experience of the surgeon and the service seems to have direct interference in the results.

\section{Hybrid tReatment}

An alternative strategy for the management of patients with $C A B G$ indication and those with significant carotid stenosis is the hybrid procedure. It consists of PCI (angioplasty and stent placement) combined with CABG. It may be synchronous (performed at the same surgical time) or staged (performed at two different times), and associated with CABG with or without ECC. It is another therapeutic alternative based on the experience of certain services, in series of cases, single-center studies and retrospective analyzes. Although there are no multicenter and prospective studies that evaluate the superiority and safety of this therapeutic approach to the detriment of others, it is another alternative for the treatment of patients with coronary artery disease and carotid stenosis in institutions with structure and experience to carry out hybrid procedures. ${ }^{20}$

The synchronic approach, using percutaneous treatment with stent implantation in carotid lesions $(\geq 60 \%$ symptomatic or $\geq 70 \%$ asymptomatic) followed immediately by $\mathrm{CABG}$, showed an incidence of $2.2 \%$ of $\mathrm{CVA} /$ death after 30 days and absence of neurological complications related to the percutaneous procedure and AMI. In this single-center, prospective and nonrandomized study $(\mathrm{n}=90)$, synchronic hybrid treatment was a reasonable option for the selected group of patients. ${ }^{21}$

The prospective/multicenter SHARP trial $(n=101)$ evaluated PCI associated with CABG at the same surgical time in high-risk patients (EuroESCORE $\geq 5$ ). ${ }^{22}$ Simultaneous hybrid technique demonstrated $98 \%$ success in the procedure and $2 \%$ cumulative incidence of AMI/CVA/ death within 30 days. It thus demonstrated a feasible and promising approach for this group of patients. ${ }^{22}$

Retrospective evaluation of the CARE ${ }^{23}$ (Carotid Artery Revascularization) registry evaluated the clinical characteristics of patients undergoing carotid endarterectomy and percutaneous intervention of carotid lesions immediately before CABG. Despite regional variations, patients undergoing percutaneous intervention had more advanced vascular disease, but less pre-surgical risk. ${ }^{23}$

Patients with symptomatic carotid stenosis are four times more likely to develop neurological complications during CABG perioperative period. The hybrid treatment was also evaluated in this group of patients (previous TIA/ CVA) in a prospective/single-center study $(\mathrm{n}=57)$. The hybrid procedure was shown to be a viable alternative for the treatment of this high-risk group, although the strategy also lacks studies with a higher level of evidence for recommendation to the detriment of other therapeutic options in this context. ${ }^{24}$

A prospective cohort compared the staged hybrid treatment (prophylactic PCI followed by CABG) with CABG (non-ECC) in 112 patients with significant carotid stenosis and CABG indication. Prophylactic percu- 


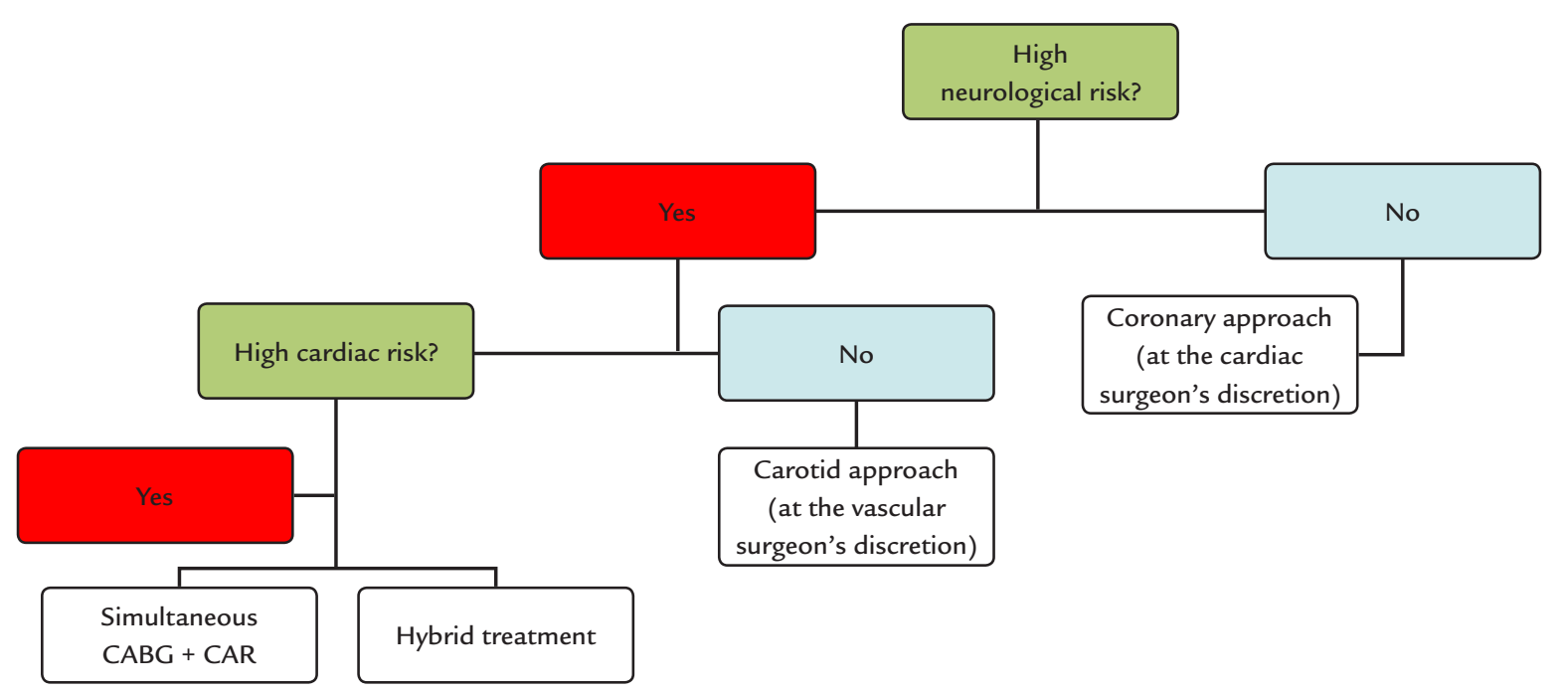

FIGURE 1 Suggested algorithm for therapeutic management of concurrent carotid and coronary artery disease. CABG: surgical myocardial revascularization; CAR: carotid artery revascularization surgery.

High neurological risk: Clinical variables: symptomatic patient (previous stroke or TIA, amaurosis fugax, ischemic or infarction areas in CNS images, even without previous neurological symptoms). Angiographic variables: bilateral carotid stenosis $70-99 \%$, unilateral carotid stenosis $70-99 \%+$ contralateral occlusion.

High cardiac risk, clinical variables: unstable angina, CCS III-IV angina, acute coronary syndrome (AMI, STEMI or non-STEMI). Angiographic variables: left coronary artery lesion greater than 70\%, or proximal anterior descending $(A D)$ artery greater than $90 \%$, or $A D$ and proximal circumflex $(C X)>70 \%$, one of them greater than $90 \%$.

taneous carotid stenosis did not reduce the risk of CVA in patients undergoing CABG, except for the subgroup of symptomatic patients (CVA/TIA) with bilateral carotid obstruction, in whom hybrid staged treatment could present a better neurological outcome in centers experienced and qualified for such procedure. ${ }^{19}$

Comparing CABG alone versus PCI + CABG (11) performed within a mean interval of 5-6 weeks, there is a trend in absolute numbers of higher risk of death, CVA and AMI with combined surgery, respectively $0.9,3.6$ and $1.8 \%$ vs. $3.2,6.4$ and $6.4 \%$, but without statistical significance. We emphasize that this study was performed by a medical center with extensive experience in carotid angioplasty and should be taken into account when observing the results.

The lack of standardization of current studies, for instance the surgical technique (percutaneous intervention versus endarterectomy with or without a filter basket), demographic and symptomatic profile of patients, and a small number of patients, often without randomization, make comparisons and broad definition of the best approach difficult. A feasible percentage, which would function as a treatment target, would be $<3 \%$ in the rate of complications following carotid angioplasty in asymptomatic patients, and $<6 \%$ in symptomatic patients. ${ }^{10,25}$

\section{Conclusion}

As already mentioned, the association of carotid and coronary atherosclerosis is very prevalent, with no con- sensus to date on which sequence of surgical approaches is the safest. In fact, greater importance should be given to intraoperative care, focusing on strict control of systemic blood pressure, avoiding extreme BP levels and including careful evaluation of the aorta during clamping and cannulation, as well as monitoring of cerebral oxygenation. ${ }^{2}$ The risks inherent to the procedure should be considered (higher CVA rate in revascularization surgeries in the presence of carotid disease and higher rate of AMI in carotid surgeries concomitant with significant $\mathrm{CAD}$ ) in the therapeutic decision (Figure 1). Individualization of treatment, use of less invasive techniques (PCI whenever possible or endovascular treatment of carotid arteries), and shared decisions with the Heart Team should be encouraged. Surely the maxim that advocates treatment of the most severe entity in the first place has a place in this scenario.

\section{Conflict of interest}

The authors declare no conflict of interest.

\section{Resumo}

Abordagem da doença coronariana e carotídea concomitante: epidemiologia, rastreamento e tratamento

A concomitância entre doença arterial coronária e doença carotídea é conhecida e já bem documentada. Fato é, porém, que, a despeito dos métodos de rastreio dessas condições 
e da evolução do tratamento cirúrgico, pouco se tem conseguido em termos de redução de risco de complicações no perioperatório. As publicações são escassas, sendo em sua maior parte compostas por relatos ou séries de caso. Há pouco consenso sobre qual a melhor abordagem terapêutica inicial (revascularização miocárdica versus carotídea), bem como sobre a melhor técnica a ser empregada (cirurgia com ou sem uso de circulação extracorpórea, tratamentos híbridos, etc.). Os autores realizaram uma revisão da evidência nesse cenário clínico, pontuando questões pragmáticas que ajudem na decisão terapêutica.

Palavras-chave: doença das coronárias, doenças das artérias carótidas, revascularização miocárdica.

\section{References}

1. Naylor AR, Mehta Z, Rothwell PM, Bell PR. Carotid artery disease and stroke during coronary artery bypass: a critical review of the literature. Eur J Vasc Endovasc Surg. 2002; 23(4):283-94.

2. Djaiani GN. Aortic arch atheroma: stroke reduction in cardiac surgical patients. Semin Cardiothoracic Vasc Anesth. 2006; 10(2):143-57.

3. Sen S, Wu K, McNamara R, Lima J, Piantadosi S, Oppenheimer SM. Distribution, severity and risk factors for aortic atherosclerosis in cerebral ischaemia. Cerebrovasc Dis. 2000; 10(2):102-9.

4. Balsam LB, DeAnda A Jr. To screen or not to screen, that is the question. Or is it? J Thorac Cardiovasc Surg. 2015; 149(6):1485-6.

5. Masabni K, Raza S, Blackstone EH, Gornik HL, Sabik JF 3rd. Does preoperative carotid stenosis screening reduce perioperative stroke in patients undergoing coronary artery bypass grafting? J Thorac Cardiovasc Surg. 2015; 149(5):1253-60.

6. Akins CW, Moncure AC, Daggett WM, Cambria RP, Hilgenberg AD, Torchiana $\mathrm{DF}$, et al. Safety and efficacy of concomitant carotid and coronary artery operations. Ann Thorac Surg. 1995; 60(2):311-8.

7. Antunes PE, Anacleto G, Oliveira JM, Eugénio L, Antunes MJ. Staged carotid and coronary surgery for concomitant carotid and coronary artery disease. Eur J Cardiothorac Surg. 2002; 21(2):181-6.

8. Ogutu P, Werner R, Oertel F, Beyer M. Should patients with asymptomatic significant carotid stenosis undergo simultaneous carotid and cardiac surgery? Interact Cardiovasc Thorac Surg. 2014; 18(4):511-8

9. Naylor AR, Bown MJ. Stroke after cardiac surgery and its association with asymptomatic carotid disease: an updated systematic review and metaanalysis. Eur J Vasc Endovasc Surg. 2011; 41(5):607-24.

10. Fareed KR, Rothwell PM, Mehta Z, Naylor AR. Synchronous carotid endarterectomy and off-pump coronary bypass: an updated, systematic review of early outcomes. Eur J Vasc Endovasc Surg. 2009; 37(4):375-8.

11. Durand DJ, Perler BA, Roseborough GS, Grega MA, Borowicz LM Jr, Baumgartner WA, et al. Mandatory versus selective preoperative carotid screening: a retrospective analysis. Ann Thorac Surg. 2004; 78(1):159-66.
12. Hillis LD, Smith PK, Anderson JL, Bittl JA, Bridges CR, Byrne JG, et al. 2011 ACCF/AHA Guideline for Coronary Artery Bypass Graft Surgery. A report of the American College of Cardiology Foundation/American Heart Association Task Force on Practice Guidelines. Developed in collaboration with the American Association for Thoracic Surgery, Society of Cardiovascular Anesthesiologists, and Society of Thoracic Surgeons. J Am Coll Cardiol. 2011; 58(24):e123-210

13. Windecker S, Kolh P, Alfonso F, Collet JP, Cremer J, Falk V, et al. 2014 ESC/ EACTS Guidelines on myocardial revascularization: The Task Force on Myocardial Revascularization of the European Society of Cardiology (ESC) and the European Association for Cardio-Thoracic Surgery (EACTS) Developed with the special contribution of the European Association of Percutaneous Cardiovascular Interventions (EAPCI). Eur Heart J. 2014; 35(37):2541-619.

14. Illuminati G, Schneider F, Greco C, Mangieri E, Schiariti M, Tanzilli G, et al. Long-term results of a randomized controlled trail analyzing the role of systematic pre-operative coronary angiography before elective carotid endarterectomy in patients with asymptomatic coronary artery disease. Eur J Vasc Endovasc Surg. 2015; 49(4):366-74.

15. Dieter RS, Tomasson J, Gudjonsson T, Brown RL, Vitcenda M, Einerson J, et al. Lower extremity peripheral arterial disease in hospitalized patients with coronary artery disease. Vasc Med. 2003; 8(4):233-6.

16. Gualandro DM, Yu PC, Calderaro D, Marques AC, Pinho C, Caramelli B, et al. II diretriz de avaliação perioperatória da Sociedade Brasileira de Cardiologia. Arq Bras Cardiol. 2011; $96(3$ suppl.1):1-68.

17. Shishehbor MH, Venkatachalam S, Sun Z, Rajeswaran J, Kapadia SR, Bajzer $\mathrm{C}$ et al. A direct comparison of early and late outcomes with three approaches to carotid revascularization and open heart surgery. J Am Coll Cardiol 2013; 62(21):1948-56.

18. Lopes DK, Mericle RA, Lanzino G, Wakhloo AK, Guterman LR, Hopkins LN. Stent placement for the treatment of occlusive atherosclerotic carotid artery disease in patients with concomitant coronary artery disease. J Neurosurg. 2002; 96(3):490-6.

19. Kassaian SE, Abbasi K, Hakki Kazazi E, Soltanzadeh A, Alidoosti M, Karimi A, et al. Staged carotid artery stenting and coronary artery bypass surgery versus isolated coronary artery bypass surgery in concomitant coronary and carotid disease. J Invasive Cardiol. 2013; 25(1):8-12.

20. Gray WA. Carotid artery stenting before cardiac surgery: a promising path down a muddy road? JACC Cardiovasc Interv. 2011; 4(11):1197-9.

21. Velissaris I, Kiskinis D, Anastasiadis K. Synchronous carotid artery stenting and open heart surgery. J Vasc Surg. 2011; 53(5):1237-41.

22. Versaci F, Reimers B, Del Giudice C, Schofer J, Giacomin A, Saccà S, et al. Simultaneous hybrid revascularization by carotid stenting and coronary artery bypass grafting: the SHARP study. JACC Cardiovasc Interv. 2009; 2(5): 393-401.

23. Don CW, House J, White C, Kiernan T, Weideman M, Ruggiero N, et al. Carotid revascularization immediately before urgent cardiac surgery. practice patterns associated with the choice of carotid artery stenting or endarterectomy: a report from the CARE (Carotid Artery Revascularization and Endarterectomy) registry. JACC Cardiovasc Interv. 2011; 4(11):1200-8

24. Van der Heyden J, Van Neerven D, Sonker U, Bal ET, Kelder JC, Plokker HW, et al. Carotid artery senting and cardiac surgery in symptomatic patients. JACC Cardiovasc Interv. 2011; 4(11):1190-6.

25. Naylor AR, Cuffe RL, Rothwell PM, Bell PR. A systematic review of outcomes following staged and synchronous carotid endarterectomy and coronary artery bypass. Eur J Vasc Endovasc Surg. 2003; 25(5):380-9. 